\title{
EFFECTS OF A FAMILY INTERVENTION ON THE QUALITY OF LIFE OF WOMEN WITH RECURRENT BREAST CANCER AND THEIR FAMILY CAREGIVERS
}

\author{
LAUREL NORTHOUSE $^{\mathrm{a}, *}$, TRACE KERSHAW ${ }^{\mathrm{b}}$, DARLENE MOOD ${ }^{\mathrm{c}}$ and ANN SCHAFENACKER \\ ${ }^{\mathrm{a}}$ School of Nursing, University of Michigan, USA \\ ${ }^{\mathrm{b}}$ Department of Epidemiology and Public Health, Yale University, USA \\ ${ }^{\mathrm{c}}$ Wayne State University College of Nursing, USA
}

\begin{abstract}
SUMMARY
Background: The purpose of this study was to determine if patients with advanced breast cancer and their family caregivers, who participated in a family based intervention, report better quality of life and other psychosocial outcomes than dyads who received standard care alone.

Methods: Using a randomized clinical trial, 134 patients and their family caregivers were assigned to usual care (control) or to usual care plus the family intervention (experimental condition). Dyads were assessed at baseline, three- and six-months later. The intervention consisted of five sessions and addressed family involvement, optimistic attitude, coping effectiveness, uncertainty reduction, and symptom management.

Results: Patients in the family intervention reported significantly less hopelessness and less negative appraisal of illness than controls; their family caregivers reported significantly less negative appraisal of caregiving. Intervention effects were evident at three-months, but were not sustained at six-months. No difference was found in the quality of life of dyads in experimental or control conditions.

Conclusions: Although the family intervention had positive effects initially, these effects were not sustained over time. Future studies need to consider program dose and duration of effect, outcome measures that are more sensitive to change, and realistic end-points for patients with advanced cancer. Copyright (C) 2004 John Wiley \& Sons, Ltd.
\end{abstract}

\section{INTRODUCTION}

The stressful effects of breast cancer extend beyond the patient and into the lives of family members (Lethborg et al., 2003). This is especially the case during the recurrent phase of illness when patients report more pain, emotional distress, physical problems, and social restrictions than during the initial phase (Weitzner et al., 1999). Family members also report elevated distress during the recurrent phase, as well as problems carrying out their work, family, and social roles (Lewis and Deal, 1995; Northouse et al.,

\footnotetext{
*Correspondence to: School of Nursing, University of Michigan, 400 N. Ingalls, Ann Arbor, MI, 48109-0482, USA. E-mail: lnortho@umich.edu
}

1995a). In spite of these difficulties, there are few family-based programs of care. Comprehensive programs of care are needed for patients with recurrent breast cancer that include family caregivers.

The purpose of this study was to determine if patients with advanced breast cancer and their family caregivers who participate in a family-based intervention (The FOCUS Program) will report more favorable psychosocial outcomes than dyads that receive standard care alone. The specific aims of the study were to: (1) determine the effect of the family intervention on proximal outcomes (i.e. variables directly targeted by the intervention, including appraisal of illness or caregiving, hopelessness, uncertainty, and coping); and (2) determine the effect of the family intervention on the distal outcome of quality of life. 


\section{CONCEPTUAL FRAMEWORK}

Conceptually, this study was guided by a stress-appraisal model adapted from the work of Lazarus and colleagues (Lazarus, 2000; Lazarus and Folkman, 1984) (see Figure 1). According to the model, person, social and illness-related factors influence how people appraise and cope with an illness, which in turn affects their quality of life. A similar model was tested in prior studies with breast and colon cancer patients and their family caregivers and accounted for $54-70 \%$ of the variance in their quality of life and/or psychosocial adjustment (Northouse et al., 2000, 2001). These findings indicate that the variables identified in the model are significant predictors of psychosocial outcomes in cancer patients and their family caregivers, and therefore provide a strong conceptual basis for a clinical intervention designed to improve appraisal, coping, and quality of life for families dealing with advanced breast cancer.

This study examined the effects of the intervention on the proximal and distal outcomes shown in Figure 1. The family intervention (the FOCUS Program) was hypothesized to have a direct effect on the appraisal factors (i.e. appraisal of illness/ caregiving, uncertainty, and hopelessness) and coping, and an indirect effect on quality of life (see bold lines in Figure 1).
REVIEW OF LITERATURE

\section{Breast cancer recurrence and quality of life}

A number of studies have documented the negative effect of advanced breast cancer on the quality of life of patients and their family caregivers (Bull et al., 1999; Coristine et al., 2003; Given and Given, 1992). Patients with advanced breast cancer have poorer perceptions of their health (Frost et al., 2000), more emotional problems (Hall et al., 1996), more physical problems (Frost et al., 2000; Pinder et al., 1993), more impairment in their daily life (Frost et al., 2000; Silberfarb et al., 1980), and greater difficulty communicating with health professionals than newly diagnosed patients (Frost et al., 2000; Wilkinson, 1991). Family caregivers report as many role adjustment problems as patients do, more uncertainty about the illness than patients, and they perceive little support from others (Northouse et al., 1995b).

A number of factors have been identified in the research literature that positively influence the quality of life of patients and their family caregivers. These factors include higher family support (Bloom and Spiegel, 1984; Brady and Helgeson, 1999; Giese-Davis et al., 2000; Northouse et al., 1995a), greater optimism or less hopelessness (Carver et al., 1993; Kurtz et al.,

ANTECEDENTS PROXIMAL OUTCOMES DISTAL OUTCOMES

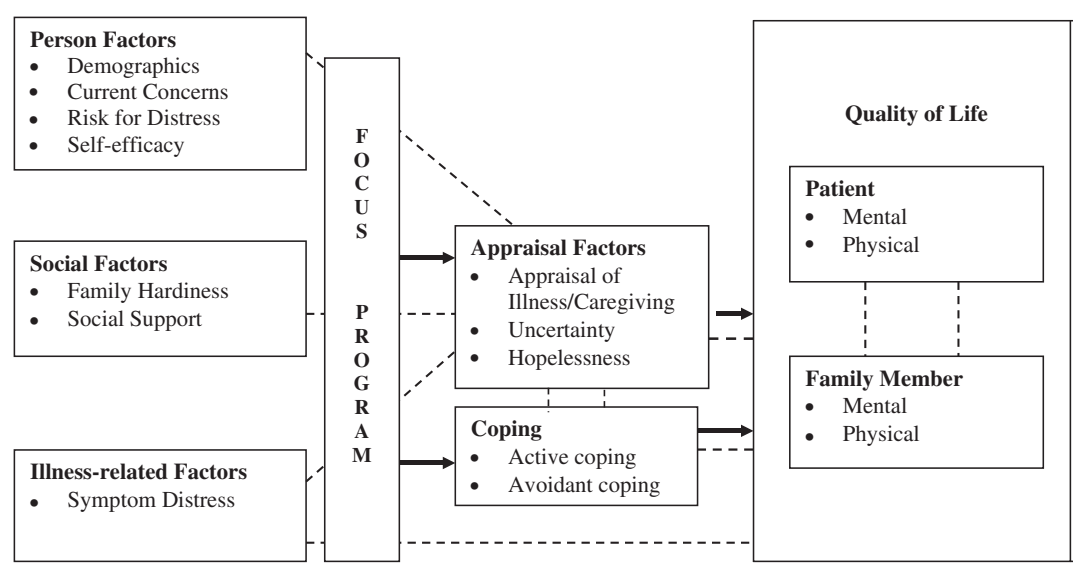

Figure 1. Theoretical model of factors affecting patient and family member quality of life. Bold lines and arrows $(\rightarrow)$ indicate hypothesized direct and indirect effects of intervention on proximal and distal outcomes. Dotted lines (-- - ) indicate significant relationships among study variables observed from previous studies. 
1995; Miller et al., 1996; Northouse et al., 1995a; Worden, 1989), less uncertainty about the illness or treatments (Mishel et al., 1984; Northouse et al., 1995a), less symptom distress (McCorkle and Quint-Benoliel, 1983; Worden, 1989), and the use of more active coping strategies (Classen et al., 1996; Hack and Degner, 1999; Heim et al., 1997). These findings provided the rationale for developing a program that facilitated family support, enhanced optimism, and encouraged active coping, while also reducing uncertainty and symptom distress. These factors became the core components of our family based intervention called The FOCUS Program.

Intervention studies with cancer patients and their caregivers

Several intervention studies have been conducted with patients and their family caregivers (Bucher et al., 2001; Christensen, 1983; Donnelly et al., 2000; Hoskins et al., 2001; Jepson et al., 1999; Kozachik et al., 2001) and a few additional studies have been conducted with caregivers alone (Bultz et al., 2000; Pasacreta et al., 2000; Toseland et al., 1995). For the most part, only a few significant intervention effects have been found in these studies. Bultz et al. (2000) found that family caregivers who participated in a psycho-educational support group reported less mood disturbance, greater confidant support, and greater marital satisfaction than caregivers in the control group. Christensen (1983) found that among couples that participated in a counseling intervention, both partners reported less emotional discomfort and higher sexual satisfaction than dyads in the control condition. McCorkle et al. (2000) found significantly longer survival rates among late stage cancer patients vs controls who participated in a home care intervention with their family caregivers. Blanchard et al. (1996) found that patients, whose spouses participated in an intervention program, reported less depression than the control group. Other investigators have reported improvement in caregivers' problem-solving ability, awareness of community resources, and knowledge following intervention (Bucher et al., 2001; Hoskins et al., 2001; Pasacreta et al., 2000), but these studies lacked control group comparisons.

Even though the preceding results are encouraging, intervention research with family caregivers has been conducted with a small number of dyads in pilot studies (Donnelly et al., 2000; Hoskins et al., 2001), plagued by low response rates and low retention rates among participants (Blanchard et al., 1996; Bucher et al., 2001), or they have been offered at times during the course of illness when dyads had few adjustment problems (Toseland et al., 1995). Prior research indicates that there is a need for family intervention research that jointly examines patient and caregiver outcomes in welldesigned clinical trials.

Based on the review of literature, we developed a family intervention that included both patients and caregivers to facilitate their communication and support. It was delivered through a combination of home visits and follow-up phone calls to decrease travel demands on participants, and was designed to be fairly brief (i.e. five contacts) to limit time demands on families.

\section{METHOD}

\section{Design}

A prospective longitudinal randomized clinical trial was designed to determine the effects of a family based intervention (The FOCUS Program) on the quality of life and other psychosocial outcomes of patients with recurrent breast cancer and their family caregivers. Dyads were: (1) assessed at baseline, (2) stratified by patients' type of current treatment (chemotherapy or a combination of therapies, hormonal therapy alone, or bone marrow transplant) and number of recurrences (first vs subsequent), and (3) randomized into the control (usual care only) or the experimental condition (usual care plus the FOCUS Program). All dyads were reassessed at three- and six-months following baseline. Detailed information about participants' quality of life at baseline (Time 1) prior to randomization has been reported previously (Northouse et al., 2002a).

\section{Sample}

Patients were eligible for the study if they had a confirmed diagnosis of recurrent breast cancer within the previous month, defined as the reappearance of breast cancer after any disease-free interval. They also were eligible if there was 
confirmation that patients' breast cancer had progressed within the previous month by laboratory test, radiologic test, or clinical exam that necessitated a change in treatment. Other patient criteria included: age 21 or older, mentally and physically able to participate, able to speak and understand English, a life expectancy of at least six-months (determined by physician or protocol nurse), and able to identify a family caregiver willing to participate in the study. Family caregiver criteria included: age 21 or older, mentally and physically able to participate, able to speak and understand English, and identified by the patient as her primary family caregiver. 'Family caregiver' was defined as the family member or significant other identified by the patient as her primary source of emotional and physical support during the recurrent phase of breast cancer and confirmed by the designated individual.

Two hundred and fifty women from four large oncology centers in the Midwest, who were told that their cancer had recurred or progressed within the previous month, were asked to participate in this study. Of these, 200 women and their family caregivers agreed to participate (response rate $80 \%$ ). Since the number of patients with Stage 1 or 2 disease was very small $(5.2 \%)$, only patients with Stage $3(10.4 \%)$ and Stage 4 disease $(84.4 \%)$ were included in the analyses for this paper in order to have a more homogeneous sample of patients with advanced breast cancer $(N=189)$. Seven additional women, who completed the baseline data collection, subsequently chose not to accept their random assignment (i.e. to either treatment or control group) and did not continue in the study. This resulted in a baseline sample size of 182 patient-family caregiver dyads; 94 dyads were randomly assigned to the experimental group and 88 dyads to the control group.

Of these 182 dyads, 134 dyads $(74 \%)$ completed follow-up assessments at 3 and 6 months, and constituted the final sample for analysis, including 69 dyads in the experimental group and 65 dyads in the control group. Among the 48 dyads who did not complete the study, there was no significant differential loss to follow-up between the experimental $(n=25)$ and control $(n=23)$ groups, $\chi^{2}(1)=0.01, p=0.94$. The majority of dyads lost to follow-up were due to the death of the patient within the six-month timeframe of the study $(n=38 ; 79 \%)$. Less common reasons for loss to follow-up among the 48 dyads included refusal to continue $(n=5,11 \%)$, patient too ill to continue $(n=2,4 \%)$, dyad relationship ended $(n=2,4 \%)$, and unable to contact the dyad $(n=1,2 \%)$. There was no difference between experimental and control groups on the reason for lost to followup, $\chi^{2}(4)=1.22, p=0.87$.

The average age of patients in the final sample $(N=134)$ was 54 years (S.D. $=11.0$; range $22-86)$ and the average age of their family caregivers was 52 years (S.D. $=14.0$; range $18-87$ ). Seventy-seven percent of the dyads were Caucasian, $19 \%$ were African American, and 4\% were Hispanic, Asian, or Native American. Both patients and family caregivers reported an average of 14 years of formal education and a median family income in the $\$ 30-50,000$ range. Most of the family caregivers who participated in the study were husbands $(62 \%)$; the remaining participants were siblings $(9 \%)$, adult daughters $(13 \%)$, adult sons $(3 \%)$, or other relatives or friends $(13 \%)$.

In terms of initial treatment, $32 \%$ had a lumpectomy, $63 \%$ a mastectomy, and $5 \%$ another type of surgery. Sixty-five percent reported evidence of disease in their adjacent lymph nodes at the time of their surgery. Fifty-three percent of the women had a family history of breast cancer. A little over half of the women $(57 \%)$ reported this was their first recurrence, while others reported this as their second $(26 \%)$, third $(9 \%)$, or fourth or greater $(8 \%)$ recurrence/progression. The average disease-free interval between initial diagnosis and first recurrence was 4.2 years. In terms of current treatment, for both experimental and control groups, approximately $66 \%$ of the patients were receiving chemotherapy or a combination of therapies, approximately $11 \%$ were receiving hormone therapy alone, and approximately $23 \%$ had a bone marrow transplant. There were no differences between the groups on type of treatment. More than half of the patients $(58 \%)$ reported having other health problems, such as hypertension or heart disease.

\section{Experimental intervention: the FOCUS program}

Patients and family caregivers randomized to the experimental intervention received their usual care plus the FOCUS Program. The FOCUS Program is a family based intervention designed to provide patients and their caregivers with information and support during the recurrent phase of breast cancer. The program consists of five core content areas, with the first letter of each area 
forming the acronym FOCUS: Family involvement, Optimistic attitude, Coping effectiveness, Uncertainty reduction, and Symptom management. Each of the five core content areas was derived from prior research and included specific interventions listed in Table 1. A more detailed description of the program has been reported previously (Northouse et al., 2002b).

The FOCUS Program consists of an initial phase and a booster phase. During the initial phase, a masters-prepared nurse conducted three home visits with the patient and her family caregiver that were spaced one month apart (approx. $1 \frac{1}{2} \mathrm{~h} /$ visit). During the booster phase, the same nurse made two prearranged, follow-up phone calls to both the patient and family caregiver (approx. $30 \mathrm{~min} /$ call). Overall, the FOCUS Program consisted of five nurse-family dyad contacts. Dyads were assessed: at baseline, at three-months after they completed the initial phase of the FOCUS Program, and at six-months after they completed the booster phase of the program.

To standardize the implementation of the FOCUS Program across various intervention nurses and sites, a 17-page protocol manual was developed that outlined the interventions for each home visit and phone call. The manual was developed in a checklist format so that interven- tion nurses could document that each of the five core content areas was covered with all dyads. In addition to the core content areas, the program had flexibility that enabled nurses to tailor program content to the needs of specific family dyads. For example, some dyads needed more assistance with symptom management, while others needed more assistance with maintaining optimism. Intervention staff also met regularly with the principal investigator and other intervention staff to discuss their caseload of dyads and to ensure that they were intervening in a similar manner within and across their caseloads.

\section{Instruments}

Proximal outcomes. Four proximal outcomes were measured for both patients and caregivers: appraisal, uncertainty, hopelessness, and coping. Patients' appraisal of illness was measured with the Appraisal of Illness Scale, a 27-item scale, with higher scores indicating a more negative view of the illness (Munkres et al., 1992; Oberst, 1991b). Caregivers' appraisal of caregiving was measured with the Appraisal of Caregiving Scale, a 27-item scale that assessed caregivers' views of tasks and problems associated with caregiving (Oberst, 1991a); higher scores indicate more negative

Table 1. Five core components of the FOCUS program

\begin{tabular}{|c|c|}
\hline Core component & Interventions \\
\hline 1. Family involvement & $\begin{array}{l}\text { Promote open communication } \\
\text { Encourage mutual support and teamwork } \\
\text { Identify family strengths } \\
\text { Help children in the family as needed }\end{array}$ \\
\hline 2. Optimistic attitude & $\begin{array}{l}\text { Encourage optimistic thinking } \\
\text { Help dyad share fears and concerns } \\
\text { Assist dyad to maintain hope } \\
\text { Help dyad to stay hopeful in the face of death }\end{array}$ \\
\hline 3. Coping effectiveness & $\begin{array}{l}\text { Help dyad deal with overwhelming stress } \\
\text { Encourage healthy coping and lifestyle behaviors } \\
\text { Assist caregivers to manage the demands of illness }\end{array}$ \\
\hline 4. Uncertainty reduction & $\begin{array}{l}\text { Educate dyad about disease and treatments as needed } \\
\text { Teach dyad how to be assertive to obtain additional information } \\
\text { Help dyad learn ways to live with uncertainty }\end{array}$ \\
\hline 5. Symptom management & $\begin{array}{l}\text { Assess symptoms in patient and family caregiver } \\
\text { Teach self-care strategies to manage symptoms }\end{array}$ \\
\hline
\end{tabular}


appraisal of caregiving. Adequate internal consistency and construct validity of both appraisal scales have been reported (Munkres et al., 1992; Oberst, 1991a,b). In this study, good internal consistency reliability coefficients were obtained for patients and family caregivers (alphas $=0.86$ 0.90 ) for Times $1,2,3$.

Uncertainty was measured with the Mishel Uncertainty in Illness Scale (Mishel, 1983; Mishel et al., 1984). The 28 -item community version of the scale was used for patients and a 29-item family version of the scale was used for caregivers. The one item that differed from the patient version was deleted to enable comparisons between patients' and caregivers' scores. Higher scores on the scales indicate greater uncertainty. Adequate psychometric properties of both versions of the scale have been reported previously (Mishel and Epstein, 1990). Results from the current study showed good internal consistency coefficients for patients and family caregivers (alphas $=0.84-0.88$ ) for the three assessment times.

Hopelessness was measured with the Beck Hopelessness Scale, a 20-item true and false scale, with higher scores indicating more hopelessness (Beck et al., 1974). Adequate internal consistency, concurrent and construct validity has been reported previously for the scale (Beck et al., 1974). In this study, adequate internal consistency was found when the scale was used with patients and family caregivers (alphas $=0.88-0.91$ ) at Times 1 , 2, 3.

Coping was measured with the 24-item version of the Brief COPE which assessed 12 coping strategies (self-distraction, active coping, denial, alcohol/drug use, emotional support, behavioral disengagement, venting, positive reframing, planning, use of humor, acceptance, and religion) (Carver, 1997). Higher scores on the coping subscales (two items per subscale) indicate greater use of the particular coping strategy. Two summary scales were created based on factor analysis: active coping and avoidant coping (see Kershaw et al., 2004 for more details). Results indicated slightly lower internal consistency coefficients for patients on the active coping dimension (alphas $=0.61-0.70$ ) but adequate coefficients on avoidant coping (alphas $=0.81-0.84)$ for Times 1, 2, and 3 . For family caregivers, the alphas on active coping ranged from 0.67 to 0.75 and for avoidant coping ranged from 0.80 to 0.84 for Times 1,2 , and 3 .
Distal outcomes. Quality of life was the distal outcome for both patients and caregivers and was measured using two instruments: (1) the FACT scale version three, and (2) the SF-36 Health Survey. The FACT-B (i.e. breast cancer-specific format) was used to measure patients' quality of life and the FACT-G (general format) was used to measure family caregivers' quality of life. Wording on the FACT-G was modified slightly so that caregivers reported on their own, rather than the patients' quality of life. Adequate reliability and validity of the FACT scales, and SF 36 have been reported previously (Brady et al., 1997; Cella et al., 1993; Ware et al., 1994).

Two quality of life summary scales were created from the subscales of the FACT and SF-36, based on second order factor analysis results, using structural equation modeling (see Northouse et al., 2002a for details). The two summary scales measured physical quality of life (consisting of the SF-36 subscales physical functioning, physical role, body pain, general health, and vitality and the FACT subscales physical well-being, and functional well being) and mental quality of life (consisting of the SF-36 subscales emotional role functioning, mental health, and social functioning and the FACT-G subscales social/family well being, and emotional well being). Factor scores were created for both patients and family members based on this structure. Factor scores were then converted to $T$-scores with a mean of 50 and a standard deviation of 10 so that means were on a positive scaling unit.

Demographic and medical history variables. Demographic variables and medical history variables were measured with the omega screening questionnaire (OSQ) developed by Mood (Mood and Bickes, 1989) from a clinical screening interview by Weisman and Worden (1976) and Worden (1983). The OSQ contains four sections: Demographics, Health History, Inventory of Current Concerns, and Symptoms Scale. Reliability and validity of each of the four sections, have been reportedly previously (Mood and Bickes, 1989; Mood and Streater, 1994). Other medical characteristics were measured with a researcher-designed questionnaire to obtain additional data on patients' medical characteristics and patients' and caregivers' health history. Data also were obtained on changes in patients' medical status from baseline to three and six-month follow-up using the Karnofsky 
Performance Status Scale (functional status) (Schag et al., 1984) and medical chart data. Medical chart data included information on patients' response to treatment and on whether patients had a change in treatment since the prior assessment.

\section{Procedures}

A staff member in each medical oncology clinic served as a referral source. This designated individual identified eligible patients, determined if they had an eligible family caregiver, gave them introductory letters about the study, and obtained their permission to allow a member of the research team to call them and explain the study in greater detail. Family caregivers who were not in the clinic were telephoned at home by clinic staff and informed about the study. Patients and family caregivers who were willing to learn more about the study were called by a member of the research team, who explained the study in greater detail. Dyads who agreed to participate in the study were scheduled for their first data collection session. Prior to completing research instruments, all participants signed a written consent form that was approved by the institutional review boards at the participating research sites.

\section{Data analysis plan}

A univariate approach using repeated measures analysis of variance (ANOVA) was taken to assess the effects of the intervention on the proximal outcomes. This approach was chosen because the effect of the intervention on specific variables (e.g. hopelessness, uncertainty) vs more global constructs (e.g. appraisal) would provide more direction for future modification and implementation of the intervention. The effectiveness of the intervention was evaluated by assessing the Experimental Condition (FOCUS vs Control) by Time interaction (baseline, three-months, sixmonths). Two sets of planned contrasts were conducted. The first contrast looked at differential change between the two conditions from baseline to three-months to determine if the intervention caused any initial change. The second contrast looked at differential change from baseline to sixmonths to determine if there was a sustained change or delayed change over time.

\section{RESULTS}

\section{Baseline comparisons}

The final sample who completed all aspects of the study ( $N=134$ dyads) was compared to those lost to follow-up $(N=48)$ from the baseline sample ( $N=182$ dyads) on demographic, medical, and main study variables. Results indicated that patients lost to follow-up had significantly shorter disease-free intervals from initial diagnosis to recurrence $(M=2.6$ years vs $M=4.2$ years, $t=-19.66, p<0.01)$ than patients who completed the study. In addition, patients lost to follow-up had more symptoms, $(M=8.75$ vs $M=7.31$, $t=2.19, p<0.05)$, and more uncertainty about the illness $(M=75.6$ vs $M=70.2, t=2.13, p<0.05)$ than participants who completed the study. These differences were not surprising since the majority $(79 \%)$ of patients lost to follow-up died during the study. Hence, these differences reflect a group of patients who were sicker at baseline than those who completed the study. Patients lost to followup and those retained in the study did not differ in regard to age, education, ethnicity, marital status, type of treatment, number of recurrences, stage of disease or any of the other main study variables at baseline. Results for family caregivers showed no differences on any of the demographic, health history, or main study variables between caregivers lost to follow-up and caregivers retained in the study.

Despite randomization, group differences can emerge. Therefore, we also examined differences between the intervention and control groups at baseline ( $N=134$ dyads). Two baseline differences were found: control patients had significantly less negative appraisal of illness, $t(132)=-2.00$, $p<0.05$, and less hopelessness, $t(132)=-2.11$, $p<0.05$, than intervention patients. Because of these differences, patient's negative appraisal of illness and hopelessness were controlled for in subsequent patient analyses. There were no differences between family caregivers in intervention and control group on the study variables at baseline.

We also assessed whether there may have been a differential change in the medical status of patients in the intervention and control groups from baseline to three and six-month follow-ups. There were no significant differential changes in symptom distress, $F=0.20, p=0.82$, or Karnofsky scores, $F=0.72, p=0.49$, between the two groups 
over time. In addition, the percentage of patients whose disease progressed did not differ significantly at three-months for intervention $(28 \%)$ vs control patients $(22 \%), \chi^{2}=0.65, p=0.43$, or at six-months $(25 \%$ for both groups, $p=0.99)$.

In terms of progression pattern, additional analyses indicated that $12 \%$ of the patients progressed at the three-months only, $12 \%$ progressed at six-months only, and $13 \%$ progressed at both the three- and six-month follow-ups. Overall, $37 \%$ of the patients had a progression of their disease during the six-months of the study. There was no significant relationship between group and progression pattern $\chi^{2}=0.95, p=0.81$. There also was no significant difference in the number of patients who received a change in their treatment protocol at three-months for intervention $(55 \%)$ vs control patients $(52 \%), \chi^{2}=0.11, p=0.74$, or at six-months ( 55 vs $57 \%$, respectively), $\chi^{2}=0.02$, $p=0.90$.

The preceding results indicate there were no significant differential changes in the medical status of patients in the intervention and control groups over time. However, the results also indicate that this sample of patients as a whole showed significant deterioration in their medical status during the six-months of follow-up. More than one-third of the patients had a progression of their disease, and over one-half of the patients required a change in treatment.

Because the relationship of the caregivers to the patients might influence the overall results, we also assessed whether the relationship of the caregiver to the patient (i.e. spouse caregiver vs non-spouse caregiver) moderated the effectiveness of the intervention on main outcomes. No significant moderator effects were found. Therefore, the caregivers were treated as one group for subsequent analyses.

Table 2 shows the means for main study variables at baseline, three-month follow-up, and six-month follow-up for intervention and control patients. Table 3 shows the means at the baseline, three- and six-month follow-ups for intervention and control family caregivers.

Comparisons between participants in the experimental and control groups on proximal outcomes

Patient proximal outcomes. Results of the comparisons are shown in Table 2. A significant Experimental Condition by Time effect was found for negative appraisal of illness from

Table 2. Patient differences between FOCUS intervention group and control group on appraisal, coping and quality of life scores

\begin{tabular}{|c|c|c|c|c|c|c|c|c|}
\hline & \multicolumn{3}{|c|}{ FOCUS intervention group } & \multicolumn{3}{|c|}{ Control group } & \multicolumn{2}{|c|}{ Group $\times$ time significance } \\
\hline & BASE & $3 \mathrm{MO}$ & $6 \mathrm{MO}$ & BASE & $3 \mathrm{MO}$ & $6 \mathrm{MO}$ & BASE-3 MO & $3 \mathrm{MO}-6 \mathrm{MO}$ \\
\hline Patient & $\begin{array}{l}M \\
\text { (S.D.) }\end{array}$ & $\begin{array}{l}M \\
\text { (S.D.) }\end{array}$ & $\begin{array}{l}M \\
\text { (S.D.) }\end{array}$ & $\begin{array}{l}M \\
\text { (S.D.) }\end{array}$ & $\begin{array}{l}M \\
\text { (S.D.) }\end{array}$ & $\begin{array}{l}M \\
\text { (S.D.) }\end{array}$ & $\begin{array}{l}F \\
(p)\end{array}$ & $\begin{array}{l}F \\
(p)\end{array}$ \\
\hline \multicolumn{9}{|l|}{ Appraisal } \\
\hline Negative appraisal of illness & $\begin{array}{l}3.24 \\
(0.79)\end{array}$ & $\begin{array}{l}3.03 \\
(0.74)\end{array}$ & $\begin{array}{l}3.08 \\
(0.78)\end{array}$ & $\begin{array}{l}2.96 \\
(0.81)\end{array}$ & $\begin{array}{l}3.00 \\
(0.82)\end{array}$ & $\begin{array}{l}2.98 \\
(0.81)\end{array}$ & $\begin{array}{l}4.49 \\
(0.04)^{*}\end{array}$ & $\begin{array}{l}2.34 \\
(0.13)\end{array}$ \\
\hline Uncertainty & $\begin{array}{l}69.91 \\
(13.5)\end{array}$ & $\begin{array}{l}70.13 \\
(15.2)\end{array}$ & $\begin{array}{l}70.4 \\
(14.6)\end{array}$ & $\begin{array}{l}70.48 \\
(14.1)\end{array}$ & $\begin{array}{l}70.52 \\
(15.2)\end{array}$ & $\begin{array}{l}70.24 \\
(14.1)\end{array}$ & $\begin{array}{l}0.05 \\
(0.83)\end{array}$ & $\begin{array}{l}0.48 \\
(0.49)\end{array}$ \\
\hline Hopelessness & $\begin{array}{l}4.52 \\
(4.8)\end{array}$ & $\begin{array}{l}3.56 \\
(4.3)\end{array}$ & $\begin{array}{l}4.20 \\
(4.9)\end{array}$ & $\begin{array}{l}2.98 \\
(4.0)\end{array}$ & $\begin{array}{l}3.96 \\
(4.1)\end{array}$ & $\begin{array}{l}3.46 \\
(4.0)\end{array}$ & $\begin{array}{l}9.48 \\
(0.002)^{* *}\end{array}$ & $\begin{array}{l}1.72 \\
(0.19)\end{array}$ \\
\hline \multicolumn{9}{|l|}{ Coping } \\
\hline Active coping & $\begin{array}{l}6.26 \\
(1.2)\end{array}$ & $\begin{array}{l}6.25 \\
(1.1)\end{array}$ & $\begin{array}{l}6.12 \\
(1.2)\end{array}$ & $\begin{array}{l}6.29 \\
(1.1)\end{array}$ & $\begin{array}{l}6.29 \\
(1.2)\end{array}$ & $\begin{array}{l}6.11 \\
(1.1)\end{array}$ & $\begin{array}{l}0.01 \\
(0.99)\end{array}$ & $\begin{array}{l}0.09 \\
(0.77)\end{array}$ \\
\hline Avoidant coping & $\begin{array}{l}4.06 \\
(0.92)\end{array}$ & $\begin{array}{l}4.05 \\
(0.90)\end{array}$ & $\begin{array}{l}4.13 \\
(0.96)\end{array}$ & $\begin{array}{l}3.84 \\
(0.81)\end{array}$ & $\begin{array}{l}3.91 \\
(0.77)\end{array}$ & $\begin{array}{l}3.80 \\
(0.81)\end{array}$ & $\begin{array}{l}0.23 \\
(0.64)\end{array}$ & $\begin{array}{l}0.80 \\
(0.37)\end{array}$ \\
\hline \multicolumn{9}{|l|}{ Quality of life } \\
\hline Mental quality of life & $\begin{array}{l}51.88 \\
(10.4)\end{array}$ & $\begin{array}{l}51.34 \\
(9.5)\end{array}$ & $\begin{array}{l}51.12 \\
(10.8)\end{array}$ & $\begin{array}{l}49.15 \\
(9.4)\end{array}$ & $\begin{array}{l}49.13 \\
(9.9)\end{array}$ & $\begin{array}{l}48.81 \\
(10.7)\end{array}$ & $\begin{array}{l}0.01 \\
(0.92)\end{array}$ & $\begin{array}{l}0.07 \\
(0.79)\end{array}$ \\
\hline Physical quality of life & $\begin{array}{l}51.71 \\
(9.6)\end{array}$ & $\begin{array}{l}50.80 \\
(9.3)\end{array}$ & $\begin{array}{l}49.72 \\
(9.2)\end{array}$ & $\begin{array}{l}49.62 \\
(9.3)\end{array}$ & $\begin{array}{l}49.90 \\
(9.8)\end{array}$ & $\begin{array}{l}49.80 \\
(9.7)\end{array}$ & $\begin{array}{l}0.49 \\
(0.48)\end{array}$ & $\begin{array}{l}1.74 \\
(0.19)\end{array}$ \\
\hline
\end{tabular}

$\mathrm{BASE}=$ baseline, $3 \mathrm{MO}=$ three-month follow-up interview, and $6 \mathrm{MO}=$ six-month follow-up interview.

${ }^{*} p<0.05 ;{ }^{* *} p<0.01$. 
Table 3. Family caregiver differences between FOCUS intervention group and control group on appraisal, coping, and quality of life

\begin{tabular}{|c|c|c|c|c|c|c|c|c|}
\hline & \multicolumn{3}{|c|}{ FOCUS intervention group } & \multicolumn{3}{|c|}{ Control group } & \multicolumn{2}{|c|}{ Group $\times$ time significance } \\
\hline & BASE & $3 \mathrm{MO}$ & $6 \mathrm{MO}$ & BASE & $3 \mathrm{MO}$ & $6 \mathrm{MO}$ & BASE-3 MO & $3 \mathrm{MO}-6 \mathrm{MO}$ \\
\hline Family caregiver & $\begin{array}{l}M \\
\text { (S.D.) }\end{array}$ & $\begin{array}{l}M \\
\text { (S.D.) }\end{array}$ & $\begin{array}{l}M \\
\text { (S.D.) }\end{array}$ & $\begin{array}{l}M \\
\text { (S.D.) }\end{array}$ & $\begin{array}{l}M \\
\text { (S.D.) }\end{array}$ & $\begin{array}{l}M \\
\text { (S.D.) }\end{array}$ & $\begin{array}{l}F \\
(p)\end{array}$ & $\begin{array}{l}F \\
(p)\end{array}$ \\
\hline \multicolumn{9}{|l|}{ Appraisal } \\
\hline Negative appraisal of caregiving & $\begin{array}{l}2.69 \\
(0.59)\end{array}$ & $\begin{array}{l}2.50 \\
(0.55)\end{array}$ & $\begin{array}{l}2.53 \\
(0.57)\end{array}$ & $\begin{array}{l}2.63 \\
(0.59)\end{array}$ & $\begin{array}{l}2.62 \\
(0.70)\end{array}$ & $\begin{array}{l}2.56 \\
(0.68)\end{array}$ & $\begin{array}{l}3.90 \\
(0.04) *\end{array}$ & $\begin{array}{l}0.80 \\
(0.37)\end{array}$ \\
\hline Uncertainty & $\begin{array}{l}81.58 \\
(13.6)\end{array}$ & $\begin{array}{l}78.14 \\
(14.3)\end{array}$ & $\begin{array}{l}76.19 \\
(12.9)\end{array}$ & $\begin{array}{l}81.03 \\
(13.4)\end{array}$ & $\begin{array}{l}79.69 \\
(14.4)\end{array}$ & $\begin{array}{l}78.43 \\
(13.4)\end{array}$ & $\begin{array}{l}1.13 \\
(0.29)\end{array}$ & $\begin{array}{l}1.57 \\
(0.21)\end{array}$ \\
\hline Hopelessness & $\begin{array}{l}2.96 \\
(3.0)\end{array}$ & $\begin{array}{l}2.95 \\
(3.7)\end{array}$ & $\begin{array}{l}2.62 \\
(3.3)\end{array}$ & $\begin{array}{l}3.71 \\
(4.5)\end{array}$ & $\begin{array}{l}3.83 \\
(5.01)\end{array}$ & $\begin{array}{l}3.89 \\
(4.6)\end{array}$ & $\begin{array}{l}0.07 \\
(0.80)\end{array}$ & $\begin{array}{l}1.48 \\
(0.23)\end{array}$ \\
\hline \multicolumn{9}{|l|}{ Coping } \\
\hline Active coping & $\begin{array}{l}5.75 \\
(1.2)\end{array}$ & $\begin{array}{l}5.66 \\
(1.2)\end{array}$ & $\begin{array}{l}5.41 \\
(1.2)\end{array}$ & $\begin{array}{l}5.34 \\
(1.2)\end{array}$ & $\begin{array}{l}5.17 \\
(1.3)\end{array}$ & $\begin{array}{l}5.19 \\
(1.3)\end{array}$ & $\begin{array}{l}0.19 \\
(0.67)\end{array}$ & $\begin{array}{l}1.03 \\
(0.31)\end{array}$ \\
\hline Avoidant coping & $\begin{array}{l}3.45 \\
(1.1)\end{array}$ & $\begin{array}{l}3.28 \\
(0.96)\end{array}$ & $\begin{array}{l}3.25 \\
(0.90)\end{array}$ & $\begin{array}{l}3.34 \\
(0.96)\end{array}$ & $\begin{array}{l}3.29 \\
(1.0)\end{array}$ & $\begin{array}{l}3.30 \\
(1.0)\end{array}$ & $\begin{array}{l}0.63 \\
(0.43)\end{array}$ & $\begin{array}{l}0.82 \\
(0.37)\end{array}$ \\
\hline \multicolumn{9}{|l|}{ Quality of life } \\
\hline Mental quality of life & $\begin{array}{l}49.80 \\
(10.6)\end{array}$ & $\begin{array}{l}50.46 \\
(9.7)\end{array}$ & $\begin{array}{l}50.81 \\
(12.3)\end{array}$ & $\begin{array}{l}49.19 \\
(10.8)\end{array}$ & $\begin{array}{l}49.47 \\
(10.4)\end{array}$ & $\begin{array}{l}49.21 \\
(12.0)\end{array}$ & $\begin{array}{l}0.06 \\
(0.81)\end{array}$ & $\begin{array}{l}0.32 \\
(0.57)\end{array}$ \\
\hline Physical quality of life & $\begin{array}{l}49.92 \\
(9.6)\end{array}$ & $\begin{array}{l}49.59 \\
(9.1)\end{array}$ & $\begin{array}{l}50.54 \\
(9.7)\end{array}$ & $\begin{array}{l}49.26 \\
(9.9)\end{array}$ & $\begin{array}{l}49.07 \\
(9.4)\end{array}$ & $\begin{array}{l}48.93 \\
(10.2)\end{array}$ & $\begin{array}{l}0.01 \\
(0.91)\end{array}$ & $\begin{array}{l}0.51 \\
(0.48)\end{array}$ \\
\hline
\end{tabular}

$\mathrm{BASE}=$ baseline, $3 \mathrm{MO}=$ three-month follow-up interview, and $6 \mathrm{MO}=$ six-month follow-up interview.

${ }^{*} p<0.05$.

baseline to three-months, $F(1,131)=4.49, p=0.04$. Patients who received the family intervention reported a significant decrease in their negative appraisal of illness from baseline to three-months later $(p=0.008)$, whereas control patients did not $(p=0.68)$. At the six-month follow-up, no significant difference was found between the intervention and control patients. Thus, the differential change found at three-months was not sustained at sixmonths, $F(1,131)=2.34, p=0.13$.

In addition, a significant Condition by Time effect was found on patient hopelessness from baseline to three-months, $F(1,131)=9.48$, $p=0.002$. Patients who received the family intervention showed a significant decrease in hopelessness from baseline to three-months $(p=0.03)$, whereas patients in the control group reported a significant increase in hopelessness during this time $(p=0.03)$. At six-month follow-up, no significant difference was found between intervention and control patients. The difference in hopelessness found at three months was not sustained from baseline to six-months with the experimental group, $F(1,131)=1.72, p=0.19$. In addition, no significant intervention effects were found between patients in the experimental and control groups on variables measuring uncertainty or coping at either follow-up assessment (see Table 2).

Family caregiver proximal outcomes. Results of the comparisons are shown in Table 3. A significant Experimental Condition by Time effect was found for negative appraisal of caregiving from baseline to three months, $F(1,132)=3.90$, $p=0.046$. Family caregivers who received the family intervention showed a significant decrease in negative appraisal of caregiving from baseline to three-months later $(p=0.004)$, whereas control participants did not $(p=0.89)$. However, this differential change was not sustained from baseline to six months, $F(1,132)=0.80, p=0.37$. There were no other significant differential effects between family caregivers in the experimental and control groups on uncertainty, hopelessness, and coping (see Table 3 ).

\section{Comparisons between experimental and control} groups on quality of life (distal) outcomes

Results of the repeated measures analyses of variance indicated no significant differential 
changes in quality of life over time between patients in the experimental and control group from baseline to three-months or from baseline to six-months (see Table 2). There also were no significant differential changes in the quality of life for family caregivers in the experimental and control groups (see Table 3).

\section{DISCUSSION}

This randomized clinical trial was designed to determine the effects of a family based intervention on the proximal and distal outcomes of patients with recurrent breast cancer and their family caregivers. One of the important findings of the study is that patients with recurrent breast cancer who participated in the family intervention (The FOCUS Program) reported significantly less hopelessness at three-months follow-up than did patients in the control group. While there have been a number of reports in the research literature which indicate that patients often feel a sense of despair or diminished hope when their cancer returns (Cella et al., 1990), there have been few corresponding reports of how to help advanced cancer patients manage these feelings. The findings from this study suggest that hopelessness can be addressed and that there are specific strategies to mitigate patients' sense of hopelessness during advanced cancer. A number of these strategies are included in the core content of the FOCUS Program and identified in a booklet titled 'Fostering an Optimistic Outlook' developed specifically for the intervention group. In addition, during the intervention sessions, patients and caregivers identified factors that affected their levels of optimism and they discussed specific strategies for maintaining or enhancing it, such as surrounding themselves with positive people, setting realistic goals, and focusing on the small joys in life. The increased emphasis on maintaining optimism and countering hopelessness in the intervention protocol may have accounted for the significant difference found between patients in the experimental vs the control group.

However, in spite of intervention patients' significant decrease in hopelessness, there are areas that need further exploration. There was no change in the level of hopelessness reported by family caregivers even though they participated in all aspects of the family intervention. It is possible that the intervention was directed more at reducing hopelessness in the patient than in family caregivers. Another possibility is that since caregivers had less hopelessness than patients (Northouse et al., 2002a), there might have been less need for improvement.

There was also a lack of sustained change in patients' hopelessness over time. The lower hopelessness reported by patients in the experimental group was evident only at the three-month followup assessment and not at the six-month follow-up. It is possible that the lack of sustained effect may be related to the program dose and duration. Dyads who participated in the FOCUS Program received the strongest dose of the intervention (including the optimism component) during the first three months of the program; it was during this time that dyads received three face-to-face home visits from a masters-prepared intervention nurse. During the period from three to six-months, dyads received only two follow-up phone calls, which were of shorter duration (i.e. $30 \mathrm{~min}$ ), and functioned more as brief booster sessions. A more intense dose of the intervention (e.g. longer sessions, face-to-face contact) may be needed over a sustained period of time to maintain the positive effects of the intervention in decreasing hopelessness. Other researchers also have reported a lack of intervention effect among cancer patients at extended follow-ups (Edelman et al., 1999; Mishel et al., 2002). For example, Mishel and colleagues found their strongest intervention effects at four months, just following completion of the intervention in men with prostate cancer (Mishel et al., 2002). They found that the intervention effect was less durable after the intervention stopped and contend that a longer intervention may be required to sustain initial intervention effects. The findings from our study and others suggest that further research is needed on the relationship between program dose, program duration, and intervention effects over time, especially among patients with advanced cancer whose disease continues to progress (Edelman et al., 1999).

Another important finding from this study was that patients who participated in the family intervention reported significantly less negative appraisal of the illness, and their family caregivers reported less negative appraisal of caregiving than participants in the control group. Other investigators have reported an increased sense of threat (negative appraisal) that can accompany advanced cancer and the caregiving associated with it 
(Munkres et al., 1992; Weitzner et al., 1999). Because of the detrimental effects that negative appraisals have on quality of life, interventions which alter negative appraisals are important. The opportunity for patients and caregivers to discuss their concerns about the illness with the intervention nurse enabled them to obtain additional information, learn new ways to manage the concerns, and put them into perspective. Intervention nurses spent time 'normalizing' patients' and caregivers' concerns, often pointing out that their fears and worries were not unusual, but a part of the advanced cancer experience. Intervention nurses also consistently reinforced the strengths that they observed in patients and caregivers as they managed the illness or the demands associated with caregiving, enhancing the dyads' perception that they could manage the situation. These strategies in combination may have accounted for the less threatening appraisals reported by dyads in the intervention group. However, these intervention effects were evident only at the three-month assessment and were not sustained at six-months. Patients with advanced disease and their family caregivers may have insufficient resources to counter negative appraisals as the disease continues to progress without the presence of professional support. Similar to hopelessness discussed above, patients and caregivers facing advanced cancer may need a more intense or sustained dose of the intervention to maintain the positive effect of the intervention over an extended period of time, especially in light of the progressive deterioration in the patient's medical status.

In regard to quality of life, no significant main intervention effects were found between participants in the experimental and control group, which warrants further discussion. Quality of life is often viewed as the 'gold standard' outcome in psychosocial oncology studies, and there are wellvalidated cancer-specific instruments to measure quality of life. However, some investigators have found no effect of their intervention on short (Sandgren and McCaul, 2003) or long-term quality of life (Edmonds et al., 1999) and more intervention effects on specific outcomes, such as problemsolving ability (Mishel et al., 2002), reduced helplessness (Edmonds et al., 1999), and pain (Goodwin et al., 2001). Goodwin et al. reviewed psychosocial intervention studies that used multidimensional quality of life measures, and found that only two out of eight studies produced significant effects in quality of life (Goodwin et al., 2003). This may suggest that the global construct of quality of life is less sensitive to intervention effects in psychosocial studies, and particularly in patients with advanced cancer. Goodwin et al. contend that researchers should tailor their choice of outcome measures to the specific intervention being evaluated to ensure that treatment effects are captured, and not rely solely on health-related quality of life measures (Goodwin et al., 2003). Another consideration would be to assess biological outcomes (e.g. biological measures of stress and functioning) in conjunction with self-report psychosocial assessments.

Another important quality of life issue to consider is the extent to which quality of life can be improved in patients with advanced cancer whose disease continues to progress. In this study, nearly $20 \%$ of the patients died prior to completing the study, even though all participants were expected to have a six-month life expectancy. An additional one-third of the patients had progression of their disease and over $50 \%$ required a change in treatment. In such a seriously ill sample of patients, it may be more realistic to maintain day-to-day mental and physical functioning, to promote comfort, and to increase their ability to live in the present rather than to expect long-term improvements in overall quality of life. As outcome studies are planned with very ill patients with advanced disease and their caregivers, researchers will need to select outcomes are that are amenable to change and select end-points that are realistic to obtain.

There were a few limitations to the present study that need to be addressed. First, a number of analyses were conducted which increased the possibility that some findings may have occurred by chance alone (i.e. Type 1 error). However, since this was the first test of the family intervention, we thought it was essential to examine a number of possible intervention effects. Second, while a number of important variables were assessed in the study, we may have inadvertently excluded some variables that could have been affected by the family intervention. For example, we received anecdotal reports from some dyads that the family intervention enhanced their ability to communicate more openly with one another about the advanced cancer. Although initially we viewed family communication as a process variable, it may have been an important outcome variable directly effected by the intervention, and warranting inclusion in future family based studies. Third, 
no cost-effectiveness measures were included in the study. In a time of limited health care resources, we need to determine program costs and assess resource utilization expenditures that may be affected by the intervention (e.g. decreased unplanned office visits and phone calls) to more adequately determine the value-added cost of the intervention vs standard care.

Finally, the findings point to areas of future research in the development and testing of family based interventions with cancer patients and their caregivers. Although patients with advanced breast cancer and their family caregivers in this study reported high satisfaction with the family intervention (Northouse et al., 2002b), the intervention effects were limited, suggesting a need for outcome measures that are more sensitive to those effects. There also is a need for investigators to examine the inner workings of various intervention programs to determine if altering aspects of the intervention or its delivery can enhance intervention effects. Future studies also need to examine program dose and the effect of program dose (brief vs extended) on intervention outcomes. Also, future research needs to examine ways to target programs of care to patients and their family caregivers who appear to be at risk of poorer long-term adjustment to the effects of cancer. Finally, investigators may need to rethink the 'goals' in studies of patients with advanced illness. It may be more realistic to try to 'maintain' than to 'improve' quality of life in patients with advanced cancer.

In summary, this study provided an initial test of a family-based intervention for patients with advanced breast cancer and their family caregivers (the FOCUS Program). Patients who received the family intervention reported significantly less hopelessness and less negative appraisal of illness at three months follow-up than controls. Their family caregivers also reported less negative appraisal of caregiving. Given the stressful effect that cancer has on the lives of patients with advanced breast cancer and their family caregivers, more family-based intervention programs are needed to assist patients as well as their family caregivers to manage the effects of the illness.

\section{ACKNOWLEDGEMENTS}

This study was supported by a grant from the American Cancer Society.

\section{REFERENCES}

Beck AT, Weissman A, Lester D, Trexler L. 1974. The measurement of pessimism: The hopelessness scale. J Consult Clin Psychol 42: 861-865.

Blanchard C, Roseland R, McCallion P. 1996. The effects of a problem-solving intervention with spouses of cancer patients. J Psychosoc Oncol 14: 1-21.

Bloom JR, Spiegel D. 1984. The relationship of two dimensions of social support to the psychological well-being and social functioning of women with advanced breast cancer. Soc Sci Med 19: 831-837.

Brady MJ, Cella DF, Mo F et al. 1997. Reliability and validity of the functional assessment of cancer therapy-breast quality-of-life instrument. J Clin Oncol 15: 974-986.

Brady SS, Helgeson VS. 1999. Social support and adjustment to recurrence of breast cancer. $J$ Psychosoc Oncol 17: 37-55.

Bucher JA, Loscalzo M, Zabora J, Houts PS, Hooker C, BrintzenhofeSzoc K. 2001. Problem-solving cancer care education for patients and caregivers. Cancer Practice 9: 66-70.

Bull AA, Meyerowitz BE, Hart S, Mosconi P, Apolone G, Liberati A. 1999. Quality of life in women with recurrent breast cancer. Breast Cancer Res Treatment 54: 47-57.

Bultz BD, Speca M, Brasher PM, Geggie PH, Page SA. 2000. A randomized controlled trial of a brief psychoeducational support group for partners of early stage breast cancer patients. Psycho-Oncology 9: 303-313.

Carver CS. 1997. You want to measure coping but your protocol's too long: consider the brief COPE. Int $J$ Behav Med 4: 92-100.

Carver CS, Pozo C, Harris SD et al. 1993. How coping mediates the effect of optimism on distress: A study of women with early stage breast cancer. J Personal Soc Psychol 65: 375-390.

Cella D, Tulsky D, Gray G et al. 1993. The functional assessment of cancer therapy scale: development and validation of the general measure. $J$ Clin Oncol 11: 570-579.

Cella DF, Mahon SM, Donovan MI. 1990. Cancer Recurrence as a Traumatic Event. Behav Med 16: 15-22.

Christensen DN. 1983. Postmastectomy couple counseling: An outcome study of a structured treatment protocol. J Sex Mar Ther 9: 266-275.

Classen C, Koopman C, Angell K, Spiegel D. 1996. Coping styles associated with psychological adjustment to advanced breast cancer. Health Psychol 15: 434-437.

Coristine M, Crooks D, Grunfeld E, Stonebridge C, Christie A. 2003. Caregiving for women with advanced breast cancer. Psycho-Oncology 12: 709-719.

Donnelly JM, Kornblith AB, Fleishman S et al. 2000. A pilot study of interpersonal psychotherapy by 
telephone with cancer patients and their partners. Psycho-Oncology 9: 44-56.

Edelman S, Bell DR, Kidman AD. 1999. A group cognitive behaviour therapy programme with metastatic breast cancer patients. Psycho-Oncology 8: 295-305.

Edmonds CV, Lockwood GA, Cunningham AJ. 1999. Psychological response to long-term group therapy: A randomized trial with metastatic breast cancer patients. Psycho-Oncology 8: 74-91.

Frost MH, Suman VJ, Rummans TA et al. 2000. Physical, psychological and social well-being of women with breast cancer: The influence of disease phase. Psycho-Oncology 9: 221-231.

Giese-Davis J, Hermanson K, Koopman C, Weibel D, Spiegel D. 2000. Quality of couples' relationship and adjustment to metastatic breast cancer. J Family Psychol 14: 251-266.

Given B, Given CW. 1992. Patient and family caregiver reaction to new and recurrent breast cancer. $J \mathrm{Am}$ Med Womens Assoc 47: 201-206.

Goodwin P, Black JT, Bordeleau LJ, Ganz PA. 2003. Health-related quality of life measurement in randomized clinical trials in breast cancer-taking stock. J Nat Cancer Inst 95: 263-281.

Goodwin PJ, Leszcz M, Ennis M, Koopmans J, Vincent L, Guther H. 2001. The effect of group psychosocial support on survival in metastatic breast cancer. $N$ Eng $J$ Med 345: 1719-1726.

Hack TF, Degner LF. 1999. Coping with breast cancer: A cluster analytic approach. Breast Cancer Res Treatment 54: 185-194.

Hall A, Fallowfield LJ, A'Hern RP. 1996. When breast cancer recurs: A 3 year prospective study of psychological morbidity. The Breast J 2: 197-203.

Heim E, Valach L, Schaffner L. 1997. Coping and psychosocial adaptation: Longitudinal effects over time and stages in breast cancer. Psychosom Med 59: 408-418.

Hoskins CN, Haber J, Budin WC et al. 2001. Breast cancer: Education, counseling, and adjustment-a pilot study. Psychol Rep 89: 677-704.

Jepson C, McCorkle R, Adler D, Nuamah I, Lusk E. 1999. Effects of home care on caregivers' psychosocial status. Image - the J Nurs Scholarship 31: 115-120.

Kershaw T, Northouse L, Kritpracha C, Schafenacker A, Mood D. 2004. Coping strategies and quality of life in women with advanced breast cancer and their family caregivers. Psychol Health 19: 149-156.

Kozachik SL, Given CW, Given BA et al. 2001. Improving depressive symptoms among caregivers of patients with cancer: Results of a randomized clinical trial. Oncol Nurs Forum 28: 1149-1157.

Kurtz ME, Kurtz JC, Given CW, Given B. 1995. Relationship of caregiver reactions and depression to cancer patients' symptoms, functional states and depression-a longitudinal view. Soc Sci Med 40: 837-846.
Lazarus RS. 2000. Evolution of a model of stress, coping, and discrete emotions. In Handbook of Stress, Coping, and Health, Rice VH (ed.). Thousand Oaks, CA: Sage, pp. 195-222.

Lazarus RS, Folkman S (eds). 1984. Stress, Appraisal, and Coping. Springer: New York.

Lethborg CE, Kissane D, Burns WI. 2003. 'It's not the easy part': The experience of significant others of women with early stage breast cancer, at treatment completion. Soc Work Health Care 37: 63-85.

Lewis FM, Deal LW. 1995. Balancing our lives: A study of the married couple's experience with breast cancer recurrence. Oncology Nursing Forum 22: 943-953.

McCorkle R, Quint-Benoliel J. 1983. Symptom distress, current concerns and mood disturbance after diagnosis of life-threatening disease. Soc Sci Med 17: 431-438.

McCorkle R, Strumpf NE, Nuamah IF et al. 2000. A specialized home care intervention improves survival among older post-surgical cancer patients. $J \mathrm{Am}$ Geriatr Soc 48: 1707-1713.

Miller DL, Manne SL, Kathryn T, Keates J, Dougherty J. 1996. Psychological distress and well-being in advanced cancer: The effects of optimism and coping. J Clin Psychol Med S 3: 115-130.

Mishel M, Epstein D. 1990. Uncertainty in Illness Scales: Manual. University of Arizona: Tucson, AZ.

Mishel MH. 1983. Parents' perception of uncertainty concerning their hospitalized child. Nurs Res 32: 324-330.

Mishel MH, Belyea M, Germino BB et al. 2002. Helping patients with localized prostate carcinoma manage uncertainty and treatment side effects: Nurse-delivered psychoeducational intervention over the telephone. Cancer 94: 1854-1866.

Mishel MH, Hostetter T, King B, Graham V. 1984. Predictors of psychosocial adjustment in patients newly diagnosed with gynecological cancer. Cancer Nurs 7: 291-299.

Mood D, Bickes J. 1989. Strategies to enhance self-care in radiation therapy. Oncol Nurs Forum 16(Suppl): 143.

Mood DW, Streater A. 1994. Assessing cancer patients' risk for distress. Paper presented at the Midwest Nursing Research Conference, Milwaukee, WI.

Munkres A, Oberst MT, Hughes SH. 1992. Appraisal of illness, symptom distress, self-care burden, and mood states in patients receiving chemotherapy for initial and recurrent cancer. Oncol Nurs Forum 19: 1201-1209.

Northouse L, Mood D, Kershaw T et al. 2002a. Quality of life of women with recurrent breast cancer and their family members. J Clin Oncol 20: 4050-4064.

Northouse L, Walker J, Schafenacker A et al. 2002b. A family-based program of care for women with recurrent breast cancer and their family members. Oncol Nurs Forum 29: 1411-1419. 
Northouse LL, Dorris G, Charron-Moore C. 1995a. Factors affecting couples' adjustment to recurrent breast cancer. Soc Sci Med 41: 69-76.

Northouse LL, Laten D, Reddy P. 1995b. Adjustment of women and their husbands to recurrent breast cancer. Res Nurs Health 18: 515-524.

Northouse LL, Mood D, Templin T, Mellon S, George T. 2000. Couples' patterns of adjustment to colon cancer. Soc Sci Med 50: 271-284.

Northouse LL, Templin T, Mood D. 2001. Couples' adjustment to breast disease during the first year following diagnosis. $J$ Behav Med 24: 115-136.

Oberst MT. 1991a. Appraisal of caregiving scale. Manual for Use. Wayne State University: Detroit.

Oberst MT. 1991b. Appraisal of illness scale. Manual for Use. Wayne State University: Detroit.

Pasacreta JV, Barg F, Nuamah I, McCorkle R. 2000. Participant characteristics before and 4 months after attendance at a family caregiver cancer education program. Cancer Nurs 23: 295-303.

Pinder KL, Ramirez AJ, Black ME, Richards MA, Gregory WM, Rubens RD. 1993. Psychiatric disorder in patients with advanced breast cancer: Prevalence and associated factors. Eur $J$ Cancer 29A: 524-527.

Sandgren A, McCaul KD. 2003. Short-term effects of telephone therapy for breast cancer patients. Health Psychol 22: 310-315.
Schag C, Heinrick R, Ganz P. 1984. Karnofsky performance status revisited: Reliability, validity, and guidelines. J Clin Oncol 2: 187-193.

Silberfarb PM, Maurer LH, Crouthamel CS. 1980. Psychosocial aspects of neoplastic disease: I. Functional status of breast cancer patients during different treatment regimens. Am J Psychiat 137: 450-455.

Toseland RW, Blanchard CG, McCallion P. 1995. A problem solving intervention for caregivers of cancer patients. Soc Sci Med 40: 517-528.

Ware J, Kosinski M, Heller SD. 1994. Sf-36 physical and mental summary scales. A User's Manual. New England Medical Center: Boston.

Weisman AD, Worden JW. 1976. The existential plight in cancer: Significance of the first 100 days. Int $J$ Psychiat Med 7: 1-15.

Weitzner MA, McMillan SC, Jacobsen PB. 1999. Family caregiver quality of life: Differences between curative and palliative cancer treatment settings. J Pain Symptom Manage 17: 418-428.

Wilkinson S. 1991. Factors which influence how nurses communicate with cancer patients. $J$ Adv Nurs 16: $677-688$.

Worden JW. 1983. Psychosocial screening of cancer patients. J Psychosoc Oncol 1: 1-10.

Worden JW. 1989. The Experience of Recurrent Cancer. Ca: A Cancer J Clinicians 39: 305-310. 